\title{
Mild Cognitive Impairment: Deficits in Cognitive Domains Other than Memory
}

\author{
F. Ribeiro ${ }^{a, b}$ A. de Mendonça ${ }^{a, c}$ M. Guerreiro ${ }^{a, b}$ \\ ${ }^{a}$ Dementia Clinics, Laboratories of ${ }^{b}$ Language and ${ }^{c}$ Neurosciences, Neurology Department, \\ Institute of Molecular Medicine and Faculty of Medicine of Lisbon, Lisbon, Portugal
}

\section{Key Words}

Mild cognitive impairment $\cdot$ Alzheimer's disease . Memory deficit $\cdot$ Language impairment $\cdot$ Semantic fluency

\section{Abstract}

Patients with mild cognitive impairment ( $\mathrm{MCl}$ ) typically present with memory complaints, but may have mild deficits in other cognitive domains. We compared the neuropsychological profiles of a series of consecutive $\mathrm{MCl}$ patients ( $n=116$ ) with a control group of healthy elderly subjects $(n=63)$. The presence of a memory deficit on delayed recall was consistent in the $\mathrm{MCl}$ sample, as it was an inclusion criterion in the study. Impairment on immediate recall was present in $62.6 \%$ of the patients on paragraph recall of the logical memory test and in $63.1 \%$ of the patients on the word paired-associate learning test. Remarkably, patients with $\mathrm{MCl}$ frequently had deficits in cognitive domains beyond memory. As much as $68.7 \%$ of the patients had deficits in temporal orientation, $30.2 \%$ had deficits in semantic fluency, $33.7 \%$ in the Token test, $23.4 \%$ in calculation, and $23.9 \%$ in motor initiative. If detailed neuropsychological testing is performed, the majority of $\mathrm{MCl}$ patients will have deficits in cognitive domains other than memory.

\section{KARGER}

Fax +41613061234

E-Mail karger@karger.ch www.karger.com
(C) 2006 S. Karger AG, Basel

$1420-8008 / 06 / 0216-0284 \$ 23.50 / 0$

Accessible online at:

www.karger.com/dem

\section{Introduction}

Cognitive complaints, particularly memory complaints, are common in old people. Some of these old people experience changes severe enough to seek medical help and, indeed, have objective evidence of cognitive impairment, even though they do not fulfill criteria for dementia. A number of clinical concepts have been proposed to describe this situation, namely age-associated memory impairment [1], aging-associated cognitive decline [2], cognitive impairment no dementia [3], and mild cognitive impairment (MCI) [4], among others. Different concepts have distinct diagnostic criteria, the most important differences being the type of cognitive deficits (memory or other cognitive area), reference group, and threshold to define the deficit (standard deviation, SD, of 1 or more from the mean of young adults as in age-associated memory impairment or $1.5 \mathrm{SD}$ from age- and education-adjusted mean as in $\mathrm{MCI}$ ). Not surprisingly, distinct studies have yielded different numbers for incidence, prevalence and outcome, depending on the criteria applied $[4,5]$. Even using very similar criteria, the results are clearly different, whether the sample is drawn from the community or from a memory clinic [6]. The concept of MCI has prevailed in many of the recent studies. Patients with MCI present with memory complaints of unknown etiology and perform below the norms for age and education on the neuropsychological memory tests, but they have a relatively normal general cognitive function,

Filipa Ribeiro

Laboratory of Language, Faculty of Medicine of Lisbon

Av. Prof. Egas Moniz

PT-1649-028 Lisbon (Portugal)

Tel./Fax +351217934+80, E-Mail piparibeiro@mail.telepac.pt 
maintain their activities of daily living and are not demented [4]. MCI appears to represent a transition between normal aging and early dementia, since in clinical settings patients with $\mathrm{MCI}$ show rates of conversion to dementia of about $12 \%$ per year [7]. There are now guidelines recommending that these patients should be identified and followed [8]. Certainly, since the initial formulations, the $\mathrm{MCI}$ concept emphasizes memory loss. In first place, a memory complaint is necessary, and if possible should be corroborated by an informant. In second place, a deficit in memory functions should be demonstrated by neuropsychological testing [4]. Although the criteria require that the general cognitive function is preserved, the presence of mild deficits in other cognitive domains is not specifically excluded. In fact, the possibility that patients with MCI may have multiple cognitive domains affected was clearly recognized [7]. Beyond memory, impairments in other cognitive domains such as orientation, attention, executive functions and visuospatial abilities may be found in patients with MCI $[9,10]$. In addition to the amnestic form of $\mathrm{MCI}$, the presence of additional domains of involvement is thus consistent with the formulation of multi-domain amnestic MCI.

In the present study, we evaluated a series of consecutive patients with MCI using detailed neuropsychological testing in order to determine the type and frequency of cognitive domains affected.

\section{Methods}

All patients with MCI attending the Dementia Outpatient Clinic, Hospital Santa Maria, and a Memory Clinic, Lisbon, were evaluated. Control subjects were elderly volunteers who attended two community centers in Lisbon area (where they spend several hours a week in different leisure activities).

\section{Mild Cognitive Impairment}

Inclusion criteria $[7,11]$ were as follows: (1) presence of memory complaints (preferably corroborated by an informant); (2) impaired memory function documented by scores $1.5 \mathrm{SD}$ below the normal for age and education on delayed recall of the two stories from the Logical Memory subtest of the Wechsler Memory Scales [12]; (3) maintained activities of daily living; the patient should both keep the professional, social and familial activities by clinical judgment, and have a score $<3$ on the first part (items 1-8) of the Blessed Dementia Scale [13]; (4) preserved general cognitive function, according to both clinician's impression and Mini-Mental State Examination (MMSE) score.

Exclusion criteria were: (1) the presence of dementia, according to the DSM-IV criteria [14]; (2) clinical history, imaging or laboratory tests indicating other neurological or psychiatric disorder; specifically patients with history of stroke or transient ischemic attack, brain images showing cortical or cortico-subcortical large vessel infarcts, brain hemorrhage or extensive age-related white matter changes [15] (rated $\geq 3$ on the ARWMC scale [16]) and patients with a diagnosis of major depression according to the DSM-IV criteria [14]. Subjects with any systemic disease with possible impact on cognition as well as chronic alcohol or drug abuse were also excluded.

\section{Control Group}

Inclusion criteria for the control group were: (1) age $\geq 50$ years; (2) MMSE score above cut-off; (3) living independently, with maintained activities of daily living; (4) absence of neurological or psychiatric condition; (5) no evidence of cognitive deterioration or cognitive complaints. Subjects with any systemic disease and/or taking psychoactive medications with possible impact on cognition as well as chronic alcohol or drug abuse did not qualify as controls.

\section{Procedures}

$\mathrm{MCI}$ cases were subjected to clinical history and neurological examinations, laboratorial evaluation and brain imaging (CT scan or NMR scan) [17]. The participating institutions used the same detailed clinical record protocol. Both cases and controls had a detailed neuropsychological assessment that comprised:

(1) Battery of Lisbon for the Assessment of Dementia [18]. The battery includes tests for the following cognitive domains: attention (cancellation task), semantic fluency (food products), motor and graphomotor initiatives, object naming, verbal comprehension (a modified version of the Token test), orientation, verbal and nonverbal abstraction (interpretation of proverbs and the Raven Progressive Matrices) [19], visuoconstructional abilities (cube and clock draw), calculation (basic written calculation), short term memory (digit span), learning and memory (logical memory, verbal paired-associate learning, visual memory, general information and word recall).

(2) MMSE. The normative cut-off values adjusted to the education for the Portuguese population were used [20]. Subjects had to score above 22 if they had $\leq 11$ years of education, or above 27 if they had $>11$ years of education. These cut-off values adjusted to the education levels were similar to those found in other studies (see for instance, Ostrosky-Solis et al. [21] and Uhlmann and Larson [22], for the effect of education on MMSE cut-off scores).

(3) Depression scale from the Consortium to Establish a Registry for Alzheimer's Disease [23] to evaluate the presence of depressive symptoms. Subjects were classified as having serious depressive symptoms if they scored $>4$ [24].

(4) Blessed Dementia Rating Scale [13]. Changes in everyday activities and habits were assessed by the first part of the Blessed Dementia Rating Scale (first 8 items of the scale).

(5) Familial history of cognitive deterioration or dementia was examined by questioning the $\mathrm{MCl}$ patient and the informant about the existence of relatives with signs of cognitive deterioration (memory loss or other cognitive impairment, no assistance required for basic activities of daily living) or dementia (with a clinical diagnosis, or with serious cognitive impairment and requiring assistance in basic activities of daily living), starting after 40 years of age.

For the MCI group and the control group, data from the neuropsychological assessment were standardized according to the age and education norms for the Portuguese population [18]; $z$ scores were calculated according to the equation $[z=(x-$ mean $) / S D]$. 
Table 1. Demographic variables and clinical characteristics of controls and MCI patients

\begin{tabular}{lcc}
\hline & Control $(\mathrm{n}=63)$ & $\mathrm{MCI}(\mathrm{n}=116)$ \\
\hline Age, years & $67.5 \pm 10.9(50-85)$ & $68.7 \pm 7.7(46-85)$ \\
Sex, female/male & $35 / 28$ & $77 / 39$ \\
Education, years & $6.9 \pm 4.9(0-17)$ & $8.1 \pm 4.6(0-17)$ \\
Duration of symptoms, years & not applicable & $2.1 \pm 1.4(0.5-7)$ \\
Familial history of cognitive deterioration & & \\
$\quad$ or dementia, yes/no & not performed & $62 / 54$ \\
Blessed Dementia Scale & not applicable & $1.4 \pm 0.9(0-3)$ \\
MMSE* & $28.7 \pm 1.6(21-30)$ & $26.1 \pm 2.5(20-30)$ \\
\hline
\end{tabular}

All values are expressed as mean $\pm \mathrm{SD}$ (range), except where otherwise indicated. Student's test, ${ }^{*} \mathrm{p}<0.05$.
Impairment on any test was considered if a subject scored more than $1.5 \mathrm{SD}$ below the mean for his age and education. Impairment was further categorized as mild, moderate or severe. Mild impairment was defined as a score between 1.5 and $2.5 \mathrm{SD}$ below the mean, moderate impairment as a score between 2.5 and $3.5 \mathrm{SD}$ below the mean and severe impairment as a score more than $3.5 \mathrm{SD}$ below the mean. The number of subjects $(n=179)$ would allow to detect a frequency of abnormal scores (below $1.5 \mathrm{SD}$ ) of $25 \%$ in any neuropsychological test in MCI patients, assuming that controls would have a frequency of $6.7 \%$ below $1.5 \mathrm{SD}$, as expected from the normal distribution, and considering the power 0.9 , the significance level 0.05 , a ratio $\mathrm{MCI}$ :control 2:1, and no correction for multiple comparisons.

Statistical analyses were performed using SPSS for Windows (SPSS 10; SPSS Inc, Chicago, Ill., USA). p Values $<0.05$ were considered statistically significant. Demographic and neuropsychological data from the two groups (MCI and control) were analyzed using Student's t test for numerical data and $\chi^{2}$ for categorical data. Bonferroni's correction for multiple comparisons was used where appropriate. The study was approved by the local ethics committee.

\section{Results}

One hundred and sixteen consecutive subjects fulfilling MCI criteria were enrolled from May 1999 to June 2004. Sixty-three control subjects were recruited from February to June 2004. Demographic data and clinical characteristics are shown in table 1 . All subjects in the $\mathrm{MCI}$ and control groups were Caucasian and did not differ in age, education, or sex. MMSE values were significantly lower in the MCI group. The results of neuropsychological evaluation of MCI patients and controls are presented as the means of $\mathrm{z}$ scores for each test according to age and education norms for the Portuguese population [18] (fig. 1). The memory tests, namely logical memory, word paired-associate learning and words delayed recall, as well as temporal orientation, followed by verbal comprehension (Token test) and initiative (semantic fluency) were prominently impaired in MCI patients. Remarkably, MCI scores were lower than control group scores on every test (fig. 1). After Bonferroni's correction for multiple comparisons, performances on memory tests as well as the Token test, semantic fluency, motor initiative, calculation, and graphomotor initiative were still significantly worse in patients with MCI than in controls.

The presence of a memory deficit on delayed recall was consistent in the $\mathrm{MCI}$ sample, as it was an inclusion criterion in the study and should be present in every patient. Impairment on immediate recall was present in $62.6 \%$ of the patients on paragraph recall of the logical memory test and in $63.1 \%$ of the patients on the word paired-associate learning test (fig. 2). Remarkably, patients with $\mathrm{MCI}$ frequently had deficits in cognitive domains beyond memory. As much as $68.7 \%$ of the patients had deficits in temporal orientation, $30.2 \%$ in semantic fluency, $33.7 \%$ in the Token test, $23.4 \%$ in calculation, and $23.9 \%$ in motor initiative. These frequencies were significantly different from the control group $\left(\chi^{2}\right.$ test, $\left.p<0.05\right)$ after Bonferroni's correction for multiple comparisons. In fact, less than $10 \%$ of controls performed below $1.5 \mathrm{SD}$ of the mean on each cognitive test (fig. 2).

It could be that even though patients had impairments in more than one cognitive area, memory would be the most severely affected domain. To test this hypothesis, patients were separated in three groups (mild, moderate or severe, see Methods) based on the severity of the impairment on the delayed recall of the two Wechsler stories. The number of patients with severe memory impairment and at least one other cognitive domain severely affected was small $(n=2)$, which hindered the use of the $\chi^{2}$ test. For this reason, the categories of moderate and 
Fig. 2. Frequency of $\mathrm{MCl}$ patients and controls with impairment on neuropsychological tests. Bars represent the percentage of the subjects scoring below the cut-off $(1.5$ $\mathrm{SD})$ on each of the tests. ${ }^{*} p<0.05$, after Bonferroni adjustment for multiple comparisons $\left(\chi^{2}\right.$ test).

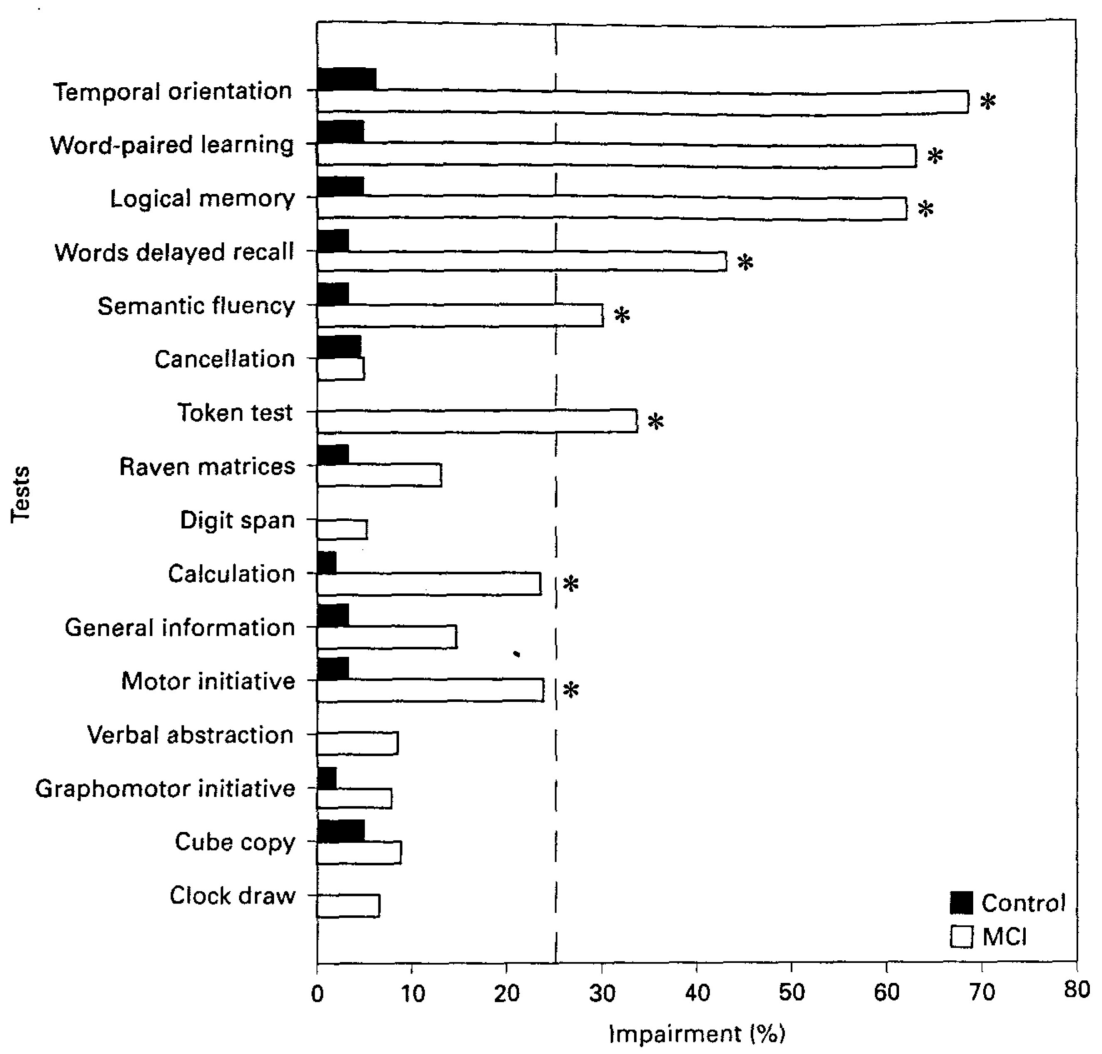

Table 2. Number of $\mathrm{MCI}$ patients with impairments in cognitive domains other than memory, according to the severity of memory impairment

\begin{tabular}{llll}
\hline & \multicolumn{2}{l}{ Severity of memory impairment } & Total, \% \\
\hline $\begin{array}{l}\text { No other cognitive impairment as severe as memory } \\
\begin{array}{l}\text { Impairment in other cognitive area at least as severe as } \\
\text { the memory impairment }\end{array}\end{array}$ & 17 & 38 & moderate/severe \\
\hline$\chi^{2}=16.6, \mathrm{p}<0.005$. & 42 & 19 & $65(47.4)$ \\
\hline
\end{tabular}

terestingly, when subjects were grouped based on the severity of the memory deficit, those with mild memory impairment often had mild deficits in other cognitive domains. This observation is not compatible with the hypothesis that MCI begins as an isolated deficit in memory, that progressively would extend to other cognitive areas as the memory impairment gets more severe. It would rather suggest that multiple mild cognitive deficits might exist at initial phases, and that with progression of the disorder memory would become more severely impaired, as typically observed in Alzheimer's disease. However, only prospective studies of patients with MCI can clarify this issue.

It could be that the high frequency of deficits we found in cognitive domains beyond memory would be for some reason particular to this study. However, the present sam- 
ple appears to be similar to other series of MCI patients selected in a clinical setting [25]. The subjects included were typically aged ( $68.7 \pm 7.7$ years old), had a low score on the first 8 items of the Blessed Dementia Scale, reflecting quite preserved activities of daily living (1.4 \pm 0.9 ; this value is similar to those obtained in other studies; see, for instance [26]), and had maintained general cognitive function as shown by normal MMSE scores (table 1). Nevertheless, it could be that persons with a relatively low education, as those included in the present study (8.1 \pm 4.6 years), could have a particular predisposition to express deficits in cognitive domains beyond memory. Certainly, the clinical experience should be taken into account when diagnosing MCI patients [27].

It is relevant to emphasize what cognitive domains other than memory were found most frequently affected in MCI patients. These were semantic fluency and complex language abilities, as evaluated by the Token test. There is evidence that these domains may be affected early in cognitive decline. Impaired verbal fluency was observed in very mildly impaired subjects who would subsequently progress to Alzheimer's disease [28]. Lan- guage impairments could be detected in a longitudinal study of patients with cognitive impairment early in the course of the decline [29], and the presence of difficulties on a naming test as well as on a visuospatial function test were found in nondemented elderly patients with memory impairment [30]. Finally, patients with MCI performed worse than controls both on a semantic fluency test and on a naming test [10].

In conclusion, $\mathrm{MCI}$ subjects exhibit an important memory deficit, but if detailed neuropsychological testing is performed, the majority of patients fulfilling criteria for MCI will have other cognitive domains affected. Because these deficits are not the same in all patients, they may be easily overlooked when the average neuropsychological measures are considered.

\section{Acknowledgements}

The authors thank Memoclínica (Memory Clinic), Lisbon, for the facilities provided. Supported by grants from Fundação para a Ciência e Tecnologia and Sociedade Portuguesa de Neurologia.

\section{References}

1 Crook T, Bartus RT, Ferris SH, Whitehouse P, Cohen GD, Gershon S; for The National Institute of Mental Health Work Group: Age-associated memory impairment: proposed diagnostic criteria and measures of clinical change. Dev Neuropsychol 1986;2:261-276.

2 Levy R: Aging-associated cognitive decline. Int Psychogeriatr 1994;6:63-68.

3 Graham JE, Rockwood K, Beattie BL, Eastwood R, Gauthier S. Tuokko H, McDowell I: Prevalence and severity of cognitive impairment with and without dementia in an elderly population. Lancet 1997;349:1793-1796.

4 Petersen RC, Smith GE, Waring SC, Ivnik RJ, Tangalos EG, Kokmen E: Mild cognitive impairment. Arch Neurol 1999;56:303-308.

5 Ritchie K, Artero S, Touchon J: Classification criteria for mild cognitive impairment. A population-based validation study. Neurology 2001;56:37-42.

6 Palmer K, Fratiglioni L, Winblad B: What is mild cognitive impairment? Variations in definitions and evolution of nondemented persons with cognitive impairment. Acta Neurol Scand 2003;107:14-20.

7 Petersen RC, Doody R, Kurz A, Mohs RC, Morris JC, Rabins PV, Ritchie K, Rossor M, Thal L, Winblad B: Current concepts in mild cognitive impairment. Arch Neurol 2001;58: 1985-1992.
8 Petersen RC, Stevens JC, Ganguli M, Tangalos EG, Cummings JL, DeKosky ST: Practice parameter: early detection of dementia: mild cognitive impairment (an evidence-based review). Report of the quality standards subcommittee of the American Academy of Neurology. Neurology 2001;56:1133-1142.

9 Griffith HR, Belue K, Sicola A, Krzywansky S, Zamrini E, Harrell L, Marson DC: Impaired financial abilities in mild cognitive impairment: a direct assessment approach. Neurology 2003;60:449-457.

10 Grundman M, Petersen RC, Ferris SH, et al.; for the Alzheimer's Disease Cooperative Study: Mild cognitive impairment can be distinguished from Alzheimer disease and normal aging for clinical trials. Arch Neurol 2004;61: 59-66.

11 de Mendonça A, Guerreiro M, Ribeiro F, Mendes T, Garcia C: Mild cognitive impairment. Focus on diagnosis. J Mol Neurosci 2004;23:13-17.

12 Wechsler D: Manuel de l'échelle clinique de mémoire. Paris, Centre de Psychologie Appliquée, 1969.

13 Blessed G, Tomlinson BE, Roth M: The association between quantitative measures of dementia and of senile change in the cerebral gray matter of elderly subjects. $\mathrm{Br} \mathrm{J}$ Psychiatry 1968;114:797-811.
14 American Psychiatric Association: Diagnostic and Statistical Manual of Mental Disorders, ed 4. Washington, American Psychiatric Association, 1994.

15 de Mendonça A, Ribeiro F, Guerreiro M, Palma T, Garcia C: Clinical significance of subcortical vascular disease in patients with mild cognitive impairment. Eur J Neurol 2005; 12: 125-130.

16 Whalund LO, Barkhof F, Fazekas F, et al.; on behalf of the European Task Force on Age-Related White Matter Changes: A new rating scale for age-related white matter changes applicable to MRI and CT. Stroke 2001;32: 1318-1322.

17 Knopman DS, DeKosky ST, Cummings JL, Chui H, Corey-Bloom J, Relkin N, Small GW, Miller B, Stevens JC: Practice parameter: diagnosis of dementia (an evidence-based review). Neurology 2001;56:1143-1153.

18 Garcia C: Alzheimer's disease: difficulties in clinical diagnosis, $\mathrm{PhD}$ dissertation, University of Lisbon, Lisbon, 1984.

19 Raven JC: The Coloured Progressive Matrices. London, Lewis HK, 1977.

20 Guerreiro M, Silva AP, Botelho MA, Leitão O, Castro Caldas A, Garcia C: Adaptação à população portuguesa na tradução do 'Mini-Mental State Examination' (MMSE) (abstract). Rev Port Neurol 1994;1:9. 
21 Ostrosky-Solis F, López-Arango G, Ardila A: Sensitivity and specificity of the Mini-Mental State Examination in a Spanish-speaking population. Appl Neuropsychol 2000;7:25-31.

22 Uhlmann RF, Larson EB: Effect of education on the mini-mental state examination as a screening test for dementia. J Am Geriatr Soc 1991;39:876-880.

23 Morris JC, Heyman A, Mohs RC, Hughes JP, van Belle G, Fillenbaum G, Mellits ED, Clark C: The Consortium to Establish a Registry for Alzheimer's Disease (CERAD). I. Clinical and neuropsychological assessment of Alzheimer's disease. Neurology 1989;39:1159-1165.
24 Mack JL, Patterson MB: Manual: CERAD Behaviour Rating Scale for Dementia. Durham, Consortium to Establish a Registry for Alzheimer's Disease, 1993.

25 Whalund LO, Pihlstrand E, Eriksdotter Jönhagen M: Mild cognitive impairment: experience from a memory clinic. Acta Neurol Scand 2003;107(suppl179):21-24.

26 Mejia S, Gutiérrez LM, Villa AR, OstroskySolis F: Cognition, functional status, education, and the diagnosis of dementia and mild cognitive impairment in Spanish-speaking elderly. Appl Neuropsychol 2004; 1 1:194-201.

27 Petersen RC: Mild cognitive impairment as a diagnostic entity. J Intern Med 2004;256:240 246.
28 Salmon DP, Thomas RG, Pay MM, Booth A, Hofstetter CR, Thal LJ, Katzman R: Alzheimer's disease can be accurately diagnosed in very mildly impaired individuals. Neurology 2002;59:1022-1028.

29 Lambon Ralph MA, Patterson K, Graham N, Dawson K, Hodges JR: Homogeneity in mild cognitive impairment and Alzheimer's disease: a cross-sectional and longitudinal study of 55 cases. Brain 2003;126:2350-2362.

30 Bozoki A, Giordani B, Heidebrink JL, Berent S, Foster NL: Mild cognitive impairments predict dementia in nondemented elderly patients with memory loss. Arch Neurol 2001;58:411416. 